increased to more than 242 , covering 168,107 hectares, since the original Conservancy was created in 1949.

In addition, there are 5 existing or proposed Marine Nature Reserves and 13 Ramsar (wetland) Sites, with many more in the pipeline for wetlands specially suited for wildfowl; there are also 241 Local Nature Reserves which are responsible to County Councils. The number of registered Sites of Special Scientific Interest (SSSIs), a few of which have raised contentions, has now risen to 5,671, of which 3,536 are in England, 1,319 in Scotland, and the remaining 816 in Wales.

Research projects sponsored by the NCC, in addition to those established by its own staff, numbered over 100 under contracts of more than $£ 2,000$ each, with many further, smaller ones. They covered subjects in agriculture and land-use, uplands, grasslands, heathlands, peatlands, and woodlands, earth sciences, coastal and inland waters, and urban environments. Research projects on birds, mammals, reptiles, amphibians, invertebrates, and rare plants, were included, as well as more general subjects such as monitoring, toxic chemicals, and socio-economic planning.

\section{Extra-British Contributions Also Impressive}

The NCC's contribution outside Britain was also impressive, for example in relation to the Ramsar Convention, the World Heritage Convention, the Bern Convention on Wildlife and Natural Habitats, and cooperation with the European Community and the Centre Naturopa. On a wider scale came the 13 UK Biosphere Reserves and the MAB Action Plan. The NCC was also active in the Tropical Forest Forum, Oil Pollution in the Gulf, and CITES; but most of all it was active through its many relations with IUCN.

Undoubtedly all these achievements and activities will be continued and, we trust, duly expanded under the new organization of Councils and Committees which has replaced the NCC. With the appointment of Lord Selborne as Chairman of the Joint Coordinating Committee, a framework for the future is complete.

\section{E. BARTON Worthington, CBE Colin Godmans \\ Furners Green, Near Uckfield Sussex TN22 3RR \\ England, UK.}

\title{
Climate Scenarios for Alpine Regions: A Collaborative Effort between ICALPE and ProClim
}

\section{Introduction}

There is widespread scientific consensus that, as global concentrations of 'greenhouse' gases increase, the global climate is likely to change. This would lead to shifts in regional climates, manifested by changes in temperature and precipitation regimes, and in the frequencies of extreme events. As a result, the distribution of plant and animal species and communities would be expected to change. An understanding of such possible changes is an essential input for planning the management of natural resources and, particularly, of protected areas in future decades.

The FUTURALP project, coordinated by the International Centre for Alpine Environments (ICALPE), situated at Le Bourget-du-Lac, France, is an exploratory step towards improved understanding of the foreseeable impacts of climate change on the ecosystems of the Alps. It is being undertaken within the European Programme on Climatology and Natural Hazards (EPOCH) of the Commission of the European Communities. The project stems from an exploratory workshop held in October 1989, with the support of IUCN, which provided the basis for the project's first report, prepared by Professor Paul Ozenda, the project's scientific adviser, and Dr Jean-Luc Borel, and published by ICALPE in July 1991. The project's time-frame is 1991-93; it involves scientists in various disciplines from Austria, France, Germany, Italy, and Switzerland.

\section{Issues Considered}

The key issues considered by FUTURALP concern the composition, functioning, and spatial distribution, of Alpine ecosystems, and how they may be affected by changes in temperature and precipitation patterns. The main objectives are to:

- concentrate on modifications of geo-ecological zonation, critical threshold parameters, and index species and communities (particularly of birds);
- produce cartographic simulations;

- evaluate potential methodologies for monitoring; and

- provide recommendations for resource management policies.

Research is focused at both the regional scale $(1: 500,000)$ and the test-area scale $(1: 50,000$ or less), Geographic Information Systems (GIS) being used at both scales. A key component of the project is a regional data-base of the Alps, at a scale of 1:500,000, to be developed at the University of Grenoble. It will include vegetation, topographic, geological, climatic, and ornithological, information.

As is shown in Fig. 1, the conceptual framework of FUTURALP includes four interlinked stages:

- compilation of data (vegetation, climatic, paleoclimatic, and ornithological);

- development of models of control of distribution (climate $\rightarrow$ vegetation; vegetation $\rightarrow$ birds; climate $\rightarrow$ birds);

- development of climatic scenarios; and

- cartographic simulations derived from these models and scenarios (vegetation and ornithological only).

The vegetation component of the project starts with the development of a coherent typology of the vegetation of the Alps by harmonizing existing typologies, particularly with reference to Professor Ozenda's monograph on the vegetation of the Alps (Ozenda, 1988). The map of vegetation, prepared according to the coherent typology, will be entered into the regional data-base. At the test-area scale, vegetation data will be compiled in GIS data-bases at the Berchtesgaden (Germany) and Mercantour (France) National Parks, using existing classifications which will be linked to the regional typology. At both scales, predictive models of vegetation-types' distributions in relation to climatic parameters will be developed, to provide the basis for cartographic simulations based on the climatic scenarios. 


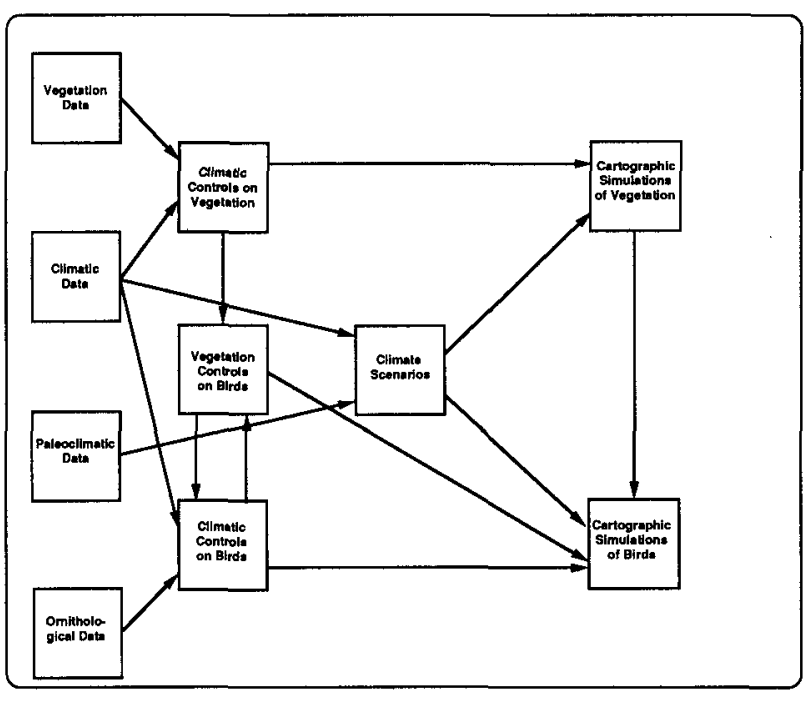

FIG. 1. Simplified conceptual framework for FUTURALP.

The ornithological component of the project starts with the compilation of bird atlases, which are available for many parts of the Alps, and their incorporation in the regional data-base. Linked to the climatic and vegetation data in the data-base, a conceptual framework of the distribution of indicator bird species and communities in relation to bioclimatic and phytoecological gradients will be developed. At the test-area scale, data on the distribution of birds will be linked to other data in the Berchtesgaden and Mercantour GISs in order to develop models of the potential distribution of bird species. Literature reviews will also be part of this process. The regional and test-area models will then be linked to the climatic scenarios, to produce cartographic simulations of possible future distributions of bird species and communities.

\section{Complementary Research Projects}

In addition to FUTURALP, a number of complementary research projects on climate change in the Alps are under way or planned, particularly by Swiss institutions. Foremost among these is the development of a flora of the Alps which is being undertaken by the Geneva Botanical Gardens and Conservatory. This project is particularly critical as a foundation for understanding the ecological impacts of climate change, as it is likely that each plant species will react differently to changes in climate. As has been shown by paleoecological research, vegetation communities rarely move as discrete entities; hence, future communities are unlikely to be the same as today's. It is hoped that, in a second phase of FUTURALP, there will be close cooperation with many other scientists working on complementary topics.

The climatic component of the project is being organized by the Swiss National Climate Programme, ProClim. The critical issues to be addressed through the use of climatic scenarios are the reaction-times of ecosystems and their components to climatic change. The first stage of this process is to assemble statistics on the distribution and means of climatic parameters, the occurrence of extreme events, and phenological criteria. Using these historical data, scenarios of the potential distribution of change in three dimensions will be developed through expert consultation.

In order to be able to quantify possible changes in Alpine ecosystems as a result of global change, it will be necessary to provide a number of relevant parameters in the form of climate scenarios. Despite an enormous effort which has been put into environmental modelling in recent years, there exists no reliable model-based climate predictions on the scales which are of interest to the FUTURALP ecosystem specialists. Present-day General Circulation Models (GCMs) have a grid-spacing of 400 $\mathrm{km}$ at best, which means that atmospheric phenomena which are smaller in scale than 2-4 grid intervals $(800-1,600 \mathrm{~km})$ are practically unresolved. GCMs are incapable of adequately resolving the Alps as a whole, let alone the test areas that are being investigated by FUTURALP.

Attempts have been made to 'scale down' from the global to the regional scale, and another EPOCH programme, Climate of the 21 st Century, has the objective of improving climate predictions through to the next century at high resolution. The techniques of downscaling by coupling of global and regional atmospheric models are still in a preliminary phase; there is still too much uncertainty in the validity of results, and the resolution of the finer grid-mesh model (essentially continental or subcontinental in scale) is still insufficient for the requirements of FUTURALP. It is therefore necessary to find an approach to climate scenarios in small-scale Alpine domains which do not necessarily require simulated atmospheric data.

Because FUTURALP has a biological/ecosystem bias, biologists are directly involved in the climatic component of the programme. Hence, rather than having atmospheric science specialists 'imposing' a number of parameters on the biologists, the latter are in a position to determine directly the climate parameters on the time- and spacescales which they consider important for their research though of course with the help and advice of climatologists. In this respect, two Swiss groups will be directly engaged in the scenario research, namely the Geneva Botanical Gardens and Conservatory, and the Systems Ecology Laboratory of the Swiss Federal Institute of Technology in Zürich. They will interact closely with the FUTURALP community on one hand, and with the Swiss National Climate Programme (ProClim), on the other. Fig. 2 gives a schematic overview of the planned approach to climate scenarios which should be quantitatively meaningful to the ecosystem specialists working in FUTURALP.

\section{Vegetation the Key}

The botanists at the Geneva Botanical Gardens and Conservatory will identify the plant species which are likely to prove most sensitive to shifts in climatic regimes, in order to make a preliminary determination of those plant communities which are most likely to react rapidly to changes in meteorological parameters. A description, or mapping using GIS techniques, of these species will help to locate the regions for which the scenarios are required. With support from FUTURALP and ProClim scientists, a summary will be made (by the systemsecology group at ETH Zürich) of the climatic conditions under which these communities exist today. This will include the average and extreme or limiting values of temperature, humidity, precipitation, snow-cover dura- 


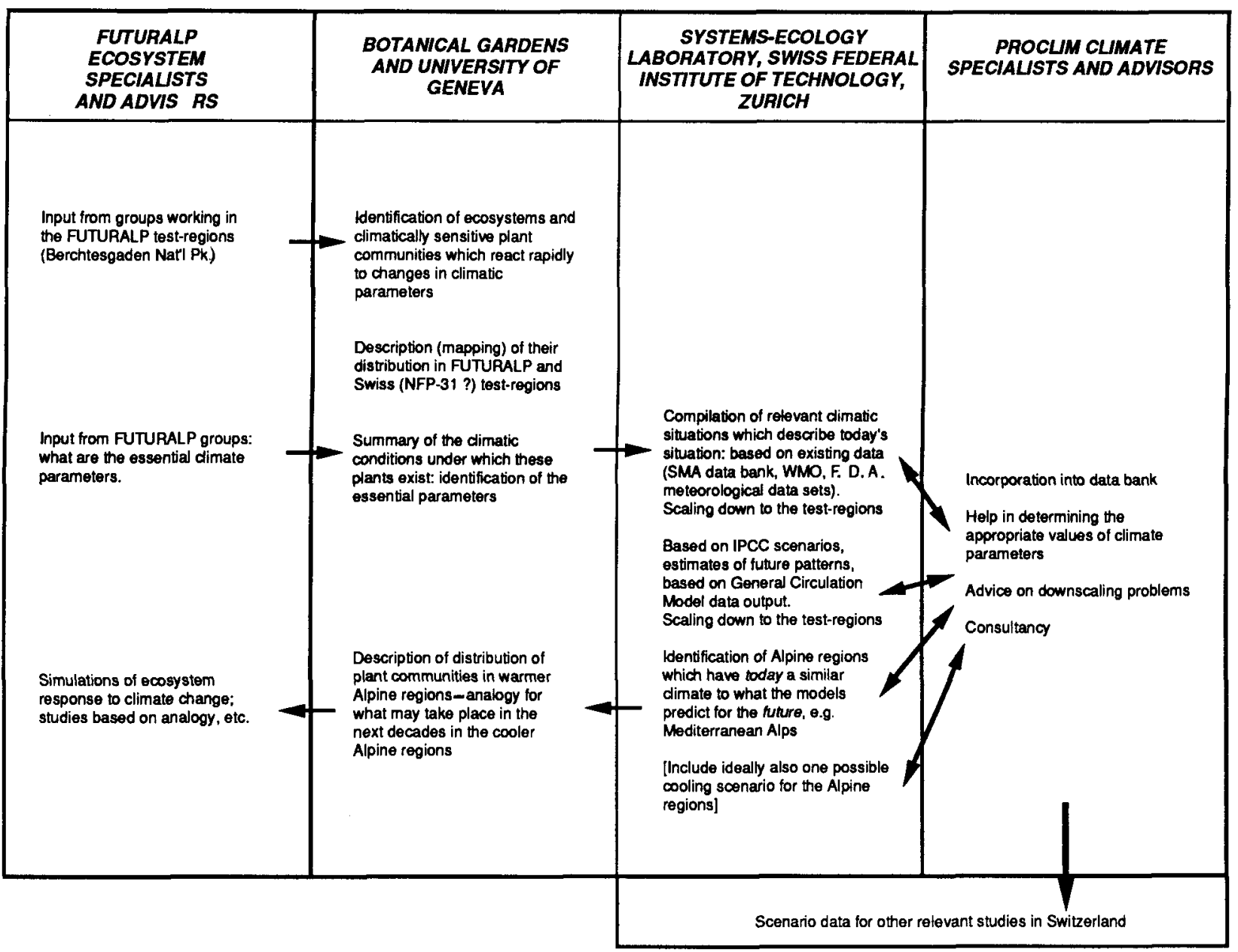

Fig. 2. Suggested working structure for the FUTURALP / ProClim Project.

tion, and surface radiation balance, on daily, monthly (or seasonal), and yearly, scales. Spatial scales would, ideally, be as fine as a $250 \mathrm{~m}$ grid (used by certain GIS specialists in Switzerland), and certainly on a regional scale would be compatible with the grid spacing of mesoscale atmospheric models, which could help in the understanding of the three-dimensional distribution of dynamic and thermodynamic variables in complex terrain.

When once present-day 'climate signatures' for the appropriate study regions have been defined, a number of future climate scenarios will be established on the basis of the IPCC report on Climate Change (Houghton et al., 1990). The scenarios should be capable of providing quantitative estimates of temperature and moisture for FUTURALP test areas under different assumptions of global change. Other important climate factors affecting vegetation and fauna should be included as part of the present and future scenarios - such as the surface energy budget, snow-cover duration, exposure to extreme weather conditions, etc.

It should be noted here that the present project has the objective of proposing climate scenarios and not predictions, a scenario being a possible or plausible picture of future climate trends with no measure as to the probability of its actually occurring, which would be more the objective of a prediction. However, a scenario can provide the necessary guidelines for a wide range of impact studies.

\section{Conclusion}

When once future scenarios have been established, it would be of interest to investigate which Alpine regions today experience climatic conditions that are close to those which the scenarios are suggesting for tomorrow. One plausible consequence of global warming could be that the cooler northern Alps may come to have a more Mediterranean-type climate as climatic belts shift northwards. It may then be possible to describe the distribution of the chosen plant species and vegetation types in today's warmer Alpine regions, and to estimate the rate and extent of migration of the species along different altitudinal levels - with the assumption that the vegetation and fauna can adapt to abrupt climate change, and that they will find at higher altitudes the soil type and other necessary environmental conditions to ensure the continued existence of the species.

The data will be included on a computerized data-bank which should be of easy access to all scientists who are 
interested in the impacts of climate change on the natural environment. The concept of a climate data-base system is at present being investigated by ProClim, for FUTURALP and other Swiss climate-relevant research projects.

\section{REFERENCES}

Houghton, J.T., Jenkins, G.J. \& Ephraums, J.J. (1990). Climate Change: The IPCC Scientific Assessment. Cambridge University Press, Cambridge, England, UK: 365 pp.

OzEnDA, P. (1988). Die Vegetation der Alpen im europäischen Gebirgsraum. Fischer, Stuttgart, Germany: $353 \mathrm{pp}$.
Martin Beniston, Programme Director

ProClim - The Swiss National

Climate Programme

Hirschengraben 11, PO Box 7613

3001 Bern, Switzerland,

$\&$

Martin F. Price

ICALPE - International Centre for Alpine Environment

Le Bourget-du-Lac, France.

\section{Vegetational Boom or Bust in Arid Australia}

Australia is a country with a Western life-style and a Third World type of economy. Well over $70 \%$ of its land area, including most of the interior, is classed as arid or semi-arid. During the 50,000 or more years before the arrival of Europeans, the Aboriginals altered the vegetation of the country very greatly. Their use of fire kept the landscape in various stages of ecological succession that made it suitable for the maintenance of a variety of game-animals but, at the same time, they may also have been responsible for hunting to extinction a rich megafauna of giant wombats and kangaroos.

Much of the land is used for cattle ranching, but the carrying capacity is generally low - despite the fact that the countryside supports a surprisingly rich flora (Fig. 1). Thus, many of the more arid parts of Australia are quite unlike the deserts of Africa, Asia, and America, in that they are much more richly vegetated. This applies even to the endless dunes of the Simpson Desert. On these grow xerophytic, drought-adapted grasses, shrubs, and even trees, although it is the hottest and most arid region of the continent. The rainfall is exceedingly irregular, and periods of drought often extend for decades. Two or three times a century, however, there may be years of extremely heavy precipitation and consequent flooding. Enough water is then trapped below-ground to keep the trees and shrubs alive until rain again falls in quantity.

The vegetation in central Australia is widely dominated by 'mulga' (Acacia spp.) and other shrubs, and by 'spinifex' or porcupine (Triodia and Plectrachne spp.) grasses, which are some of the world's hardiest grasses. As the central roots and leaves of the original plants exhaust the soil and die, the outer parts of the tussocks take root in fresh soil, forming new plants, so that rings of them develop around the dead centres. The needle-sharp spines of the porcupine grasses provide protection, and the leaves and culms shade, for many animals - including reptiles, birds, mammals, and of course insects.

The Australian arid zone supports a great diversity of soils and soil characteristics, often over relatively short distances. Sand-dunes may abut on plains of cracking clay, and calcareous earths may lie adjacent to crusty 'duplex' soils strewn with a surface cover of gravel and stones. The Simpson Desert consists mainly of longitudinal dunes extending for several hundreds of kilometres and situated more than one kilometre apart. They are so large that they can be distinguished in satellite photographs of the area.

Further south, 'mallee' is the dominant vegetation

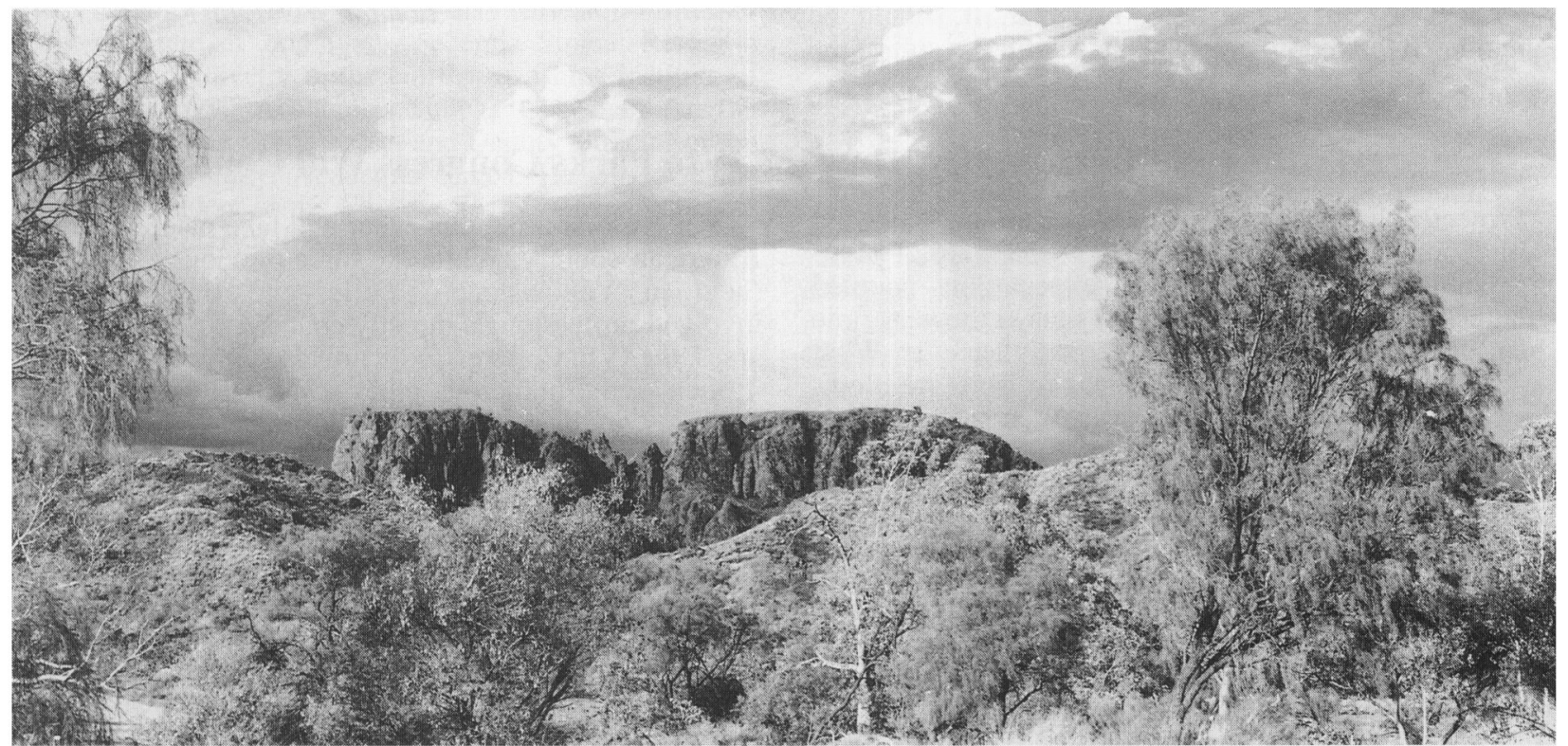

FIG. 1. The landscape of Central Australia is bisected by the well-vegetated MacDonnell Range. The variable topography supports a surprisingly rich flora. Photo: J.L. Cloudsley-Thompson. 